\title{
Effect of Cold Temperature Durations on the Emergence and Parasitization Efficiency of Laboratory Reared Trichogramma chilonis (Ishii)
}

\section{S. Vigneswaran, Dharmrajsinh M. Jethva, Pankaj S. Wadaskar* and Tushar K. Balas}

\author{
Biocontrol Research Laboratory, Department of Entomology, College of Agriculture, \\ Junagadh Agricultural University, Junagadh - 362 001, Gujarat, India \\ *Corresponding author
}

\begin{abstract}
A B S T R A C T
Keywords

Egg parasitoid,

Emergence,

Parasitization,

Storage,

Trichogramma.

Article Info

Accepted:

12 April 2017

Available Online:

10 May 2017

The result over fitness life parameters of Trichogramma revealed that the percentage emergence of Trichogramma recorded after 5 days of storage at different temperature revealed that $10^{\circ} \mathrm{C}$ gave significantly highest emergence of parasitoid $(96.20 \%)$ and was similar to control (97.4\%) however; other temperatures, 12,14 and $16^{\circ} \mathrm{C}$ showed $90.90 \%$, $89.43 \%$ and $88.33 \%$ emergence of Trichogramma, respectively. At $10^{\circ} \mathrm{C}$, the highest parasitism percentage $(96.00 \%)$ was observed and further decreased to $53.66 \%$ at $10^{\circ} \mathrm{C}$ when stored for up to 30 days whereas, the lowest parasitism percentage assessed at 16 $(89.83 \%)$ and $6^{\circ} \mathrm{C}(90.03 \%)$. The maximum adult longevity measured, while it was stored at $6^{\circ} \mathrm{C}$ (4.50 days), whereas shortest adult longevity noted at $16^{\circ} \mathrm{C}$ (3.00 days). Further, adult longevity was decreased from 4.26 to 0.00 days when stored at $10^{\circ} \mathrm{C}$ from 5 to 50 days. At $6^{\circ} \mathrm{C}$, Trichogramma gave considerable emergence (76.13-20.63\%) and parasitization (91.46-42.83\%) from 5 to 50 days storage, whereas at 12,14 and $16^{\circ} \mathrm{C}$, development was completed during storage. It was evident that storage at $10^{\circ} \mathrm{C}$ and $6^{\circ} \mathrm{C}$ were very conducive for life parameters of Trichogramma to get short term and long storage, respectively.
\end{abstract}

\section{Introduction}

Trichogramma species are widely used egg parasitoids for biological control of insect pests of different crops through augmentation and release. T. chilonis and T. achaeae have been promoted to use in controlling cabbage leaf eating caterpillars (Krishnamoorthy, 2012). Among the Trichogramma species the egg parasitoid, T. chilonis is the dominant species in India (Nagarkatti and Nagaraja, 1979). It is a very aggressive parasitoid and has the ability to increase their capability, sometimes gives near to $100 \%$ parasitism depending upon the availability of favorable condition. It is a natural enemy of many harmful lepidopterous insect pests of crops and vegetables (Jalali and Singh, 1993). Trichogramma has been used against the lepidopterous pests of cotton, cabbage, apple and tomato (Smith, 1996). They parasitize the eggs of more than 400 lepidopteran pest species (Khan et al., 2004 and Doyon and Boivin, 2005).

Mass rearing of bioagents is a prerequisite of biocontrol programme; this needs a regular and sufficient production of easily culturable factitious insect hosts for mass culturing of any bioagent (Wadaskar et al., 
2015).Trichogramma species is one of the most widely used biological control agent due to its easy rearing in insectaries and vigorous parasitism on eggs of target hosts. Thus, good quality egg parasitoid, T. chilonis could be utilized through inundative release for the management of many lepidopterous insect pest (Bhushan et al., 2012 and Fand et al., 2013).

Cold storage technique must ensure the availability of sufficient numbers (Tezze and Botto, 2004) and quality of egg parasitoids (Bigler, 1994) at the time of release. Therefore, the development of storage techniques for bio-control agents is considered of utmost importance to provide flexibility and efficiency in mass production, to synchronize a desired stage of development for peak release, and to make available standardized stocks for use in research (Greenberg et al., 1996; Leopold, 1998 and Ravensberg, 1992). Besides, cold storage can permit a more cost-effective production schedule (Glenister and Hoffmann, 1998) providing a means to conserve biological control agents when not immediately needed (Pitcher et al., 2002).

To get high rate of emergence in laboratory in hot summer, artificial manipulation in temperature is necessary for successful rearing (Rajendran, 1999). As stated above, there is a demand for information in relation to the mass rearing, emergence and parasitization ability of $T$. chilonis for successful implementation of bio control programmes. Hence, in this report, hypothesis can be drawn to evaluate the effect of a range of cold storage periods on the subsequent performance of $T$. chilonis to assess the effects of such storage on the emergence and parasitization efficiency of laboratory reared T. chilonis on eggs of its factitious host Corcyra cephalonica.

\section{Materials and Methods}

The present investigations on influence of storage on the emergence and parasitization efficiency of laboratory reared Trichogramma was carried out at Biocontrol Research Laboratory, JAU, Junagadh.

Experiment was conducted to find out the optimum storage temperature and duration for the parasitoid, T. chilonis at pupal stage in the BOD incubators. 200 eggs of Corcyra were pasted on the $17 \times 11 \mathrm{~cm}$ paper card strips and exposed for $24 \mathrm{hrs}$ to the one day age old parasitoids confined in test tubes. A drop of $50 \%$ pure honey was provided as adult feed through sterilized absorbent cotton which was placed inside the test tube. Host eggs on strips after exposure of $24 \mathrm{hrs}$ to the parasitoids were taken out from test tube and kept under standard laboratory conditions i.e., $28 \pm 1^{0} \mathrm{C}$, and $65 \pm 5 \%$ RH (Nadeem et al., 2010).

These parasitized cards in the pupal stage were stored at six different temperature regimes viz., $6,8,10,12,14$ and $16^{\circ} \mathrm{C}$ each at $5,10,15,20,25,30,40$ and 50 days in biological oxygen demand (BOD) incubators with complete darkness. After completing the respective storage duration, the parasitoid strips were taken out from the BOD incubator and placed at the standard conditions, where they were emerged after 1-3 days.

\section{Observations recorded}

The storage period was recorded precisely. At each temperature and storage period, per cent emergence, parasitism and longevity of adults were observed with meticulous care. Percentage of parasitism which was calculated by number of blackened eggs/number of total eggs $\times 100$ and longevity was calculated as days from the day of emergence to day of death. 


\section{Results and Discussion}

\section{Per cent emergence of $T$. chilonis}

The percentage emergence of Trichogramma recorded after 5 days of storage at different temperature revealed that $10^{\circ} \mathrm{C}$ gave significantly highest emergence of parasitoid $(96.20 \%)$ and lowest (76.13\%) from $6^{\circ} \mathrm{C}$ (Table 1). At ten days storage, the highest (94.10\%) emergence was observed from Trichogramma parasitoids after held at $10^{\circ} \mathrm{C}$ storage. emergence percentage. At $10^{\circ} \mathrm{C}$ the highest $(92.23 \%)$ emergence percentage after storage for fifteen days and at $6^{\circ} \mathrm{C}(55.30 \%)$ the least emergence was noted. At twenty days, pupal storage emphatically discloses the significant results on emergence percentage. The highest emergence percentage of Trichogramma obtained from $12^{0} \mathrm{C}(66.06 \%)$ and the lowest $(43.63 \%)$ from $6^{\circ} \mathrm{C}$.

The delineated results emphasize significant emergence percentage of Trichogramma after stored for twenty five days. The highest emergence percentage of Trichogramma obtained from $8^{0} \mathrm{C}(43.33 \%)$ was statistically at par with $10(41.00 \%)$ and $12^{\circ} \mathrm{C}(41.70 \%)$. The lowest emergence percentage was observed at 14 and $16^{\circ} \mathrm{C}$ emergence was utterly occluded (Table 1 ). At $6^{\circ} \mathrm{C}$ emergence percentage seemed moderately $(32.86 \%)$. The results revealed significant demarcation on emergence percentage of Trichogramma after thirty days storage. The highest emergence percentage of Trichogramma obtained from $10^{\circ} \mathrm{C} \quad(36.66 \%)$. The second highest emergence percentage of Trichogramma evaluated at $12^{\circ} \mathrm{C}(32.93 \%)$ which was statistically at par with $6^{\circ} \mathrm{C}(30.60 \%)$ and $8^{0} \mathrm{C}$ (31.93\%). Apparently the emergence percentage of Trichogramma after storage for forty days obviously divulged significant results. The highest emergence percentage recorded at $6^{0} \mathrm{C}(26.96 \%)$. Lowest emergence percentage recorded, at $8^{0} \mathrm{C}(18.76 \%)$. Adult emergence was entirely thwarted at 10,12, 14 and $16^{\circ} \mathrm{C}$. After fifty days of storage the highest emergence percentage recorded at $6^{\circ} \mathrm{C}$ $(20.63 \%)$. Lowest emergence percentage recorded, at $8^{\circ} \mathrm{C}(10.43 \%)$. Adult emergence was entirely thwarted at $10,12,14$ and $16^{\circ} \mathrm{C}$. The present result indicated that the parasitized Corcyra eggs could be stored for 50 days at low temperature $\left(6^{0} \mathrm{C}\right)$ for long duration storage. It was evidenced from the above results that the emergence of Trichogramma was decreased with increasing storage temperatures and days intervals for storage.

The present results enunciated the considerable emergence of adults up to fifty days at $6^{\circ} \mathrm{C}$ and it pertinent with findings of Gharbi (2014) who reported that the emergence rate was 87.56 percent at $15^{\circ} \mathrm{C}$ but significantly decreased to 45.32 percent at $35^{\circ} \mathrm{C}$

\section{Per cent parasitism of $T$. chilonis}

The result on per cent parasitism of Trichogramma revealed that after five days storage, the parasitism percentage was differed according to different low temperatures. At $10^{\circ} \mathrm{C}$, the highest parasitism percentage $(96.00 \%)$ was observed (Table 2). However, the lowest $(90.03 \%)$ parasitism percentage of Trichogramma observed from $16^{0} \mathrm{C}$. The empirical data showed significant difference in results on parasitization percentage of $T$. chilonis, after stored for ten days at different low temperatures. The highest parasitism percentage of Trichogramma obtained, when it was reared at $10^{\circ} \mathrm{C}(94.30 \%)$ which was statistically at par with $8^{0} \mathrm{C}(93.70 \%)$. The lowest parasitism percentage of Trichogramma assessed, when it was reared at $16(89.83 \%)$ and $6^{\circ} \mathrm{C}$ $(90.03 \%)$, which was statistically at par with each other. 
Table.1 Emergence percentage of $T$. chilonis after stored at various low temperatures

\begin{tabular}{|c|c|c|c|c|c|c|c|c|}
\hline & \multicolumn{8}{|c|}{ Emergence (\%) at different storage duration (Days) } \\
\hline Temp. & 5 & 10 & 15 & 20 & 25 & 30 & 40 & 50 \\
\hline $6^{0} \mathrm{C}$ & $60.77(76.13)$ & $50.32(59.23)$ & $48.04(55.30)$ & $41.34(43.63)$ & $34.97(32.86)$ & $33.58(30.60)$ & $31.28(26.96)$ & $27.01(20.63)$ \\
\hline $8^{0} \mathrm{C}$ & $76.79(94.53)$ & 73.55 (91.93) & $71.37(89.70)$ & $53.67(64.86)$ & $41.16(43.33)$ & $34.40(31.93)$ & $25.67(18.76)$ & $18.84(10.43)$ \\
\hline $10^{0} \mathrm{C}$ & $79.08(96.20)$ & $76.18(94.10)$ & $73.90(92.23)$ & $53.98(65.40)$ & $39.81(41.00)$ & $37.26(36.66)$ & $4.05(0.50)$ & $4.05(0.50)$ \\
\hline $12^{0} \mathrm{C}$ & $72.57(90.90)$ & $69.98(88.20)$ & $67.14(84.90)$ & $54.37(66.06)$ & $40.22(41.70)$ & $35.02(32.93)$ & $4.05(0.50)$ & $4.05(0.50)$ \\
\hline $14^{0} \mathrm{C}$ & $71.16(89.43)$ & $70.19(88.46)$ & $66.43(84.00)$ & $53.43(64.50)$ & $4.05(0.50)$ & $4.05(0.50)$ & $4.05(0.50)$ & $4.05(0.50)$ \\
\hline $16^{0} \mathrm{C}$ & $70.03(88.33)$ & $68.44(86.50)$ & $66.01(83.46)$ & $52.72(63.30)$ & $4.05(0.50)$ & $4.05(0.50)$ & $4.05(0.50)$ & $4.05(0.50)$ \\
\hline Control & $80.98(97.40)$ & & & & & & & \\
\hline S.Em \pm & 2.20 & 1.67 & 1.31 & 1.40 & 0.62 & 0.50 & 0.16 & 0.10 \\
\hline C.D. at $5 \%$ & 4.72 & 3.64 & 2.85 & 3.04 & 1.35 & 1.08 & 0.35 & 0.21 \\
\hline C.V.\% & 3.69 & 3.01 & 2.45 & 3.32 & 2.79 & 2.48 & 1.64 & 1.15 \\
\hline
\end{tabular}




\section{Int.J.Curr.Microbiol.App.Sci (2017) 6(5): 1191-1199}

Table.2 Parasitization percentage of $T$. chilonis after stored at various low temperatures

\begin{tabular}{|c|c|c|c|c|c|c|c|c|}
\hline & \multicolumn{8}{|c|}{ Parasitism(\%) at different storage duration (Days) } \\
\hline Temp. & 5 & 10 & 15 & 20 & 25 & 30 & 40 & 50 \\
\hline $6^{0} \mathrm{C}$ & $73.07 *(91.46)$ & 71.64(90.03) & $65.27(82.46)$ & $63.87(80.60)$ & $63.02(79.40)$ & $60.51(75.76)$ & $55.53(67.96)$ & $40.87(42.83)$ \\
\hline $8^{0} \mathrm{C}$ & $76.41(94.36)$ & $75.48(93.70)$ & $68.39(86.40)$ & $60.42(75.63)$ & $54.15(65.70)$ & $51.21(60.76)$ & $40.99(43.03)$ & $33.12(29.86)$ \\
\hline $10^{0} \mathrm{C}$ & $78.59(96.00)$ & $76.21(94.30)$ & $70.23(88.53)$ & $57.57(71.23)$ & $51.06(60.50)$ & $47.10(53.66)$ & $4.05(0.50)$ & $4.05(0.50)$ \\
\hline $12^{0} \mathrm{C}$ & $73.85(92.20)$ & $73.17(91.60)$ & $72.00(90.36)$ & $54.07(65.56)$ & $45.32(50.56)$ & $41.90(44.60)$ & $4.05(0.50)$ & $4.05(0.50)$ \\
\hline $14^{0} \mathrm{C}$ & $73.97(92.30)$ & $73.26(91.70)$ & $67.56(85.40)$ & $51.14(60.63)$ & $4.05(0.50)$ & $4.05(0.50)$ & $4.05(0.50)$ & $4.05(0.50)$ \\
\hline $16^{0} \mathrm{C}$ & $71.68(90.03)$ & $71.43(89.83)$ & $63.71(80.36)$ & $48.15(55.50)$ & $4.05(0.50)$ & $4.05(0.50)$ & $4.05(0.50)$ & $4.05(0.50)$ \\
\hline Control & $80.71(97.23)$ & & & & & & & \\
\hline S.Em \pm & 1.89 & 0.95 & 1.38 & 0.58 & 0.56 & 0.44 & 0.28 & 0.12 \\
\hline C.D. at $5 \%$ & 4.04 & 2.05 & 3.01 & 1.27 & 1.22 & 0.96 & 0.61 & 0.26 \\
\hline C.V.\% & 3.06 & 1.57 & 2.50 & 1.28 & 1.87 & 1.56 & 1.85 & 1.00 \\
\hline
\end{tabular}


Table.3 Adult longevity (days) of T. chilonis after stored at various low temperatures

\begin{tabular}{|c|c|c|c|c|c|c|c|c|}
\hline & \multicolumn{8}{|c|}{ Adult longevity (\%) at different storage duration (Days) } \\
\hline Temp. & 5 & 10 & 15 & 20 & 25 & 30 & 40 & 50 \\
\hline $6^{0} \mathrm{C}$ & 5.26 & 5.10 & 4.50 & 4.00 & 3.70 & 3.60 & 3.00 & 2.03 \\
\hline $8^{0} \mathrm{C}$ & 5.60 & 4.63 & 4.10 & 3.70 & 3.00 & 2.80 & 2.00 & 1.03 \\
\hline $10^{0} \mathrm{C}$ & 4.26 & 3.83 & 3.50 & 3.53 & 3.20 & 3.00 & 0.50 & 0.50 \\
\hline $12^{0} \mathrm{C}$ & 4.40 & 3.83 & 3.20 & 3.10 & 2.20 & 2.00 & 0.50 & 0.50 \\
\hline $14^{0} \mathrm{C}$ & 4.06 & 3.60 & 3.10 & 2.50 & 0.50 & 0.50 & 0.50 & 0.50 \\
\hline $16^{0} \mathrm{C}$ & 3.76 & 3.33 & 3.00 & 2.00 & 0.50 & 0.50 & 0.50 & 0.50 \\
\hline Control & 6.10 & & & & & & & \\
\hline S.Em \pm & 0.13 & 0.11 & 0.11 & 0.10 & 0.07 & 0.07 & 0.05 & 0.03 \\
\hline C.D. at $5 \%$ & 0.27 & 0.24 & 0.24 & 0.22 & 0.14 & 0.14 & 0.10 & 0.05 \\
\hline C.V.\% & 3.29 & 3.39 & 3.80 & 3.97 & 3.74 & 3.95 & 4.95 & 3.95 \\
\hline
\end{tabular}


The pragmatic data of Trichogramma revealed significant difference in results, when it was stored for fifteen days at different low temperatures. The utmost level of parasitization percentage assessed, while it was stored at $12^{\circ} \mathrm{C}(90.36 \%)$. Similar trend of parasitism was observed at $10^{\circ} \mathrm{C}(88.53 \%)$. The least parasitization percentage of Trichogramma noted from $16^{\circ} \mathrm{C}(80.36 \%)$, while it was statistically at par with $6^{\circ} \mathrm{C}$ $(82.46 \%)$. At twenty five and thirty days, Trichogramma pupal storage fetched significant results on parasitization by parasitoids (Table 2). The uppermost parasitization percentage of Trichogramma recorded at $6^{0} \mathrm{C}(79.40 \%, 75.76 \%)$ followed by at $8^{0} \mathrm{C}(65.70 \%, 60.76 \%)$, respectively. The highest parasitization percentage recorded after forty days storage at $6^{\circ} \mathrm{C}$ $(67.96 \%)$, while it was found lowest at $8^{0} \mathrm{C}$ $(43.03 \%)$. Emergence was totally thwarted at $10,12,14$ and $16^{\circ} \mathrm{C}$ so, there was no parasitization occurred. Trichogramma pupal storage up to fifty days brought significant results on parasitization of adults. The greatest level of parasitization recorded at $6^{\circ} \mathrm{C}$ $(42.83 \%)$ followed by at $8^{0} \mathrm{C}(29.86 \%)$. The present result indicated that the parasitized $C$. cephalonica eggs could be stored for 50 days at low temperature $\left(6^{0} \mathrm{C}\right)$ for long duration storage. It was evidenced from the above results that the parasitism of Trichogramma was decreased with increasing storage temperatures and days intervals for storage.

The present findings indicated that the highest parasitism was obtained from the $T$. chilonis held at $10^{\circ} \mathrm{C}$ after five days storage, which was close to control values. This statement utterly supported the Nadeem et al., (2010) who reported $97.4 \%$ parasitism after five days storage at $10^{\circ} \mathrm{C}$. Kosha and Brar (2000) elucidated the Trichogramma could be stored in the refrigerator and successfully utilized for 23 days without adversely affecting their parasitization efficiency.

\section{Adult longevity (days) of $T$. chilonis}

The result on adult longevity revealed that the highest longevity of Trichogramma observed from $8^{0} \mathrm{C}$ (5.60 days) whereas, 5.26 days of adult longevity was perceived when the parasitized card stored at $6^{0} \mathrm{C}$ which was found next in order (Table 3). At 10 and $12^{\circ} \mathrm{C}$, moderate longevity (4.26 and 4.40 days) obtained, which was statistically at par with each other. The shortest longevity period assessed at $16^{\circ} \mathrm{C}$ (3.76 days) and $14^{\circ} \mathrm{C}$ (4.06 days). Ten days storage of Trichogramma on adult longevity emphatically gave significant results. After stored for ten days, the lengthiest longevity recorded, when Trichogramma stored at $6^{0} \mathrm{C} \quad(5.10$ days $)$ followed by $8^{0} \mathrm{C}$ (4.63 days). The shortest longevity of parasitoids evaluated from $16^{\circ} \mathrm{C}$ (3.33 days). The moderate longevity and statistically similar results were obtained at 10,12 and $14^{\circ} \mathrm{C}$ such as $3.83,3.83$ and 3.60 days, respectively.

The maximum adult longevity measured, while it was stored at $6^{\circ} \mathrm{C}$ (4.50 days) followed by $8^{0} \mathrm{C}$ (4.10 days), whereas shortest adult longevity noted at $16^{\circ} \mathrm{C}$ (3.00 days). The $16^{\circ} \mathrm{C}$ was statistically at par with 12 (3.20 days) and $14^{\circ} \mathrm{C}$ (3.1 days). The moderate longevity seemed at $10^{\circ} \mathrm{C}$ (3.50 days). The present data revealed the significant results on adult longevity of $T$. chilonis after twenty days storage (Table 3). The utmost level of adult longevity obtained from $6^{0} \mathrm{C}$ (4.00 days) followed by at $8^{0} \mathrm{C}$ (3.70 days) which was statistically at par with $10^{\circ} \mathrm{C}$ (3.53 days). The shortest longevity assessed from $16^{\circ} \mathrm{C}$ (2.00 days). Perspicuous data expressed significant results on adult longevity of Trichogramma after twenty five and thirty days of storage. At $6^{0} \mathrm{C}$, the maximum adult longevity of 3.70 and 3.60 days was assessed, respectively. At 14 and $16^{\circ} \mathrm{C}$, adult emergence was completely occluded in twenty five and thirty days of storage. Longevity of Trichogramma after 
storage of forty and fifty days provided significant results. The adult longevity ranged from 3.00 to 1.03 at $6^{\circ} \mathrm{C}$ and $8^{0} \mathrm{C}$.

Our findings on decreased adult longevity at $8^{0} \mathrm{C}$ for prolonging storage are pertinent with the study reported by Ozder (2004), where adult longevity of egg parasitoid $T$. cacoeciae was decreased after 31 days storage at $8^{0} \mathrm{C}$. Rundel et al., (2004) exemplified the storage temperatures lower than $10^{\circ} \mathrm{C}$ and storage times 3 week or longer had a negative impact on longevity.

\section{References}

Bhushan, S., Singh, R.P. and Shankar, R. 2012. Biopesticidal management of yellow stem borer (Scirpophaga incertulas Walker) in rice. The Bioscan, 7(2): 317-319.

Bigler, F. 1994. Quality control in Trichogramma production. In: Biological Control with Egg Parasitoids, Wajnberg, E., Hassan, S.A. (Eds.), CAB International, Wallingford, UK. pp. 93-111.

Doyon, J. and Boivin, G. 2005. The effect of development time on the fitness of female Trichogramma evanscens. $J$. Insect Sci., 5(4): 5.

Fand, B.B., Suroshe, S.S. and Gautam, R.D. 2013. Fortuitous biological control of insect pests and weeds: a critical review. The Bioscan, 8(1): 1-10.

Gharbi, N. 2014. Influences of cold storage period and rearing temperature on the biological traits of Trichogramma oleae. Tunisian J. Plant Prot., 9: 143153.

Glenister, C.S. and Hoffmann, M.P. 1998. Mass-reared natural enemies: scientific, technological, and informational needs and considerations. In: Mass Reared Natural Enemies: Application, Regulation, and Needs, Ridgway, R. L.,
Hoffmann, M. P., Inscoe, M. N., Glenister, C. S. (Eds.). Thomas Say Publications in Entomology, Entomological Society of America, Lanham, M. D. pp. 242-267.

Greenberg, S.M., Nordlund, D.A. and King, E.G. 1996. Mass production of Trichogramma spp. J. Biocontrol News and Information, 17: 51-60.

Jalali, S.K. and Singh, S.P. 1993. Superior strain selection of the egg parasitoid Trichogramma chilonis (Ishii), Biological parameters. J. Biol. Control, 7: 57-60.

Khan, M.S., Farid, A., Ullah, F. and Badshah, H. 2004. Effect of host and parasitoid density on parasitism efficiency of Trichogramma chilonis Ishii. Asian J. Plant Sci., 3: 647-650.

Kosha, S.S. and Brar, S.K. 2000. Effect of storage on the emergence and parasitization efficiency of laboratory reared and field collected populations of Trichogramma chilonis (Ishii). J. Biol. Control, 14(2): 71-74.

Krishnamoorthy, A. 2012. Exploitation of egg parasitoids for control of potential pests in vegetable ecosystems in India. Comunicata Scientiae, 3(1): 1 - 15.

Leopold, R.A. 1998. Cold storage of insects for integrated pest management. In: Temper Temperature Sensitivity in Insects and Application in Integrated Pest Management, Hallman, G.J., Denlinger, D. L. (Eds.), Westview Press, Boulder, CO. pp. 235-267.

Nadeem, S., Ashfaq, M., Hamed, M. and Ahmed, S. 2010. Optimization of short and long term storage duration for Trichogramma chilonis (Ishii) (Hymenoptera: Trichogrammatidae) at low temperatures. Pak. J. Zool., 42: 6367.

Nagarkatti, S. and Nagaraja, H. 1979. The status of Trichogramma chilonis Ishi. $J$. Oriental Insects, 13: 115-117. 
Ozder, N. 2004. Effect of different cold storage periods on parasitization performance of Trichogramma cacoeciae (Hymenoptera: Trichogrammatidae) on eggs of Ephestia kuehniella (Lepidoptera: Pyralidae). J. Biocontrol Sci. and Tech., 14: 441-7.

Pitcher, S.A., Hoffmann, M.P., Gardner, J., Wright, M.G., and Kuhar, T.P. 2002. Cold storage of Trichogramma ostriniae reared on Sitotroga cerealella eggs. J. Biocontrol, 47: 525-535.

Rajendran, B. 1999. Emergence of Trichogramma chilonis from the parasitoid cards under laboratory conditions during 1996-1998. Coop. Sugar, 31: 331.

Ravensberg, W.J. 1992. Production and utilization of natural enemies in western European glasshouse crops. In: Advances in Insect Rearing for Research and Pest Management, Anderson, T.E., Leppla, N.C. (Eds.), Westview, Boulder, CO. pp. 465-487.
Rundel, B.J., Thomson, L.J. and Hoffmann, A.A. 2004. Effects of cold storage on field and laboratory performance of Trichogramma carverae (Hymenoptera: Trichogrammatidae) and the response of three Trichogramma spp. (T. carverae, $T$. brassicae, and $T$. funiculatum) to cold. Econ. J. Entomol., 97(2): 213-221.

Smith, S.M. 1996. Biological control with Trichogramma: advances, successes, and potential of their use. Ann. Rev. Entomol., 41: 375-406.

Tezze, A.A. and Botto, E.N. 2004. Effect of cold storage on the quality of Trichogramma nerudai (Hymenoptera: Trichogrammatidae). J. Biol. Control, 30: 11-16.

Wadaskar, P.S., Jethva, D.M., Vigneswaran S. and Rode, N.S. 2015. Studies on effect of temperature and relative humidity on biology of rice moth Corcyra cephalonica (Stainton) under laboratory condition. The Ecoscan, 9(1\&2): 201-204.

\section{How to cite this article:}

Vigneswaran, S., Dharmrajsinh M. Jethva, Pankaj S. Wadaskar and Tushar K. Balas. 2017. Effect of Cold Temperature Durations on the Emergence and Parasitization Efficiency of Laboratory Reared Trichogramma chilonis (Ishii). Int.J.Curr.Microbiol.App.Sci. 6(5): 11911199. doi: https://doi.org/10.20546/ijcmas.2017.605.129 